\title{
Empirical Analysis of FOSS for Its Deeper Perceptive and Better Prospects
}

\author{
Harmaninder Jit Singh Sidhu ${ }^{1}$, Sawtantar Singh Khurmi ${ }^{2}$ \\ ${ }^{1}$ Desh Bhagat University, Mandi Gobindgarh, Punjab, India. \\ ${ }^{2}$ Yadavindra College of Engineering, Talwandi Sabo, Bathinda, Punjab, India.
}

\begin{abstract}
The aim of this paper is to use an empirical approach to examine FOSS in respect of its key characteristics i.e. Usability and Maintainability. The different sub-characteristics of above mentioned characteristics and their subsequent attributes were envisaged in order to accomplish the task of FOSS exploration concerning its primary characteristics. The various attributes of FOSS were explored that are available in existing literature. The identified attributes were taken into account so as to empirically analyze FOSS. The existing attributes selected from the related work for this empirical swot up were mutually accepted by the participants at the time of conducting the pilot study. This research endeavour also takes into account the understanding, awareness and activities of diverse kinds of people allied with FOSS in one way or the other. The association of Usability and Maintainability of FOSS was also hypothesised and established through statistical analysis using fisher's exact test.
\end{abstract}

Keywords:- Maintainability of FOSS, Open source software (OSS)\Free and open source software (FOSS), OSS Characteristics, OSS Empirical Study/Analysis, OSS Platform, Usability of FOSS.

\section{INTRODUCTION}

The FOSS technologies are thriving in the modern world. In the software arena it is hard to find any corner without an open source contact. This emergence seems to be awesome. But, it is also true that FOSS is very deep rooted in the sands of time. Still its surfacing took quite a long time but against all odds. No doubt it has perseverance in the face of obstacles. The two indispensible characteristics of FOSS (i.e. Usability and Maintainability) are particularly imperative from viewpoint of its assessment when it needs to be compared with proprietary platforms. As far as Usability is concerned it refers to the capability of the product to be understood, learned, used and attractive to the user, when used under specified conditions. Another definition of Usability (ISO/IEC 9241-11, 1998) is that Usability can be defined as the extent to which a product can be used by specified users to achieve specified goals with effectiveness, efficiency and satisfaction in a specified context of use. Nielsen (1993) defines Usability as consisting of five quality components: Learnability, efficiency, memorability, errors and satisfaction.Usability can be attained through user-centred design process, Usability activities (for example, paper prototyping, heuristic evaluation, Usability testing), and through the entire development process keeping an overall focus on Usability issues (Boivie et al., 2005).Hall (2014) examines the current state of Usability in FOSS and tries to find out, why it is common to overlook Usability in Open Source Software? A popular Open Source Software called GNOME for desktop environment was used to provide just round the corner information for present structure for development and also to figure out the improvement areas. When test data was analysed it explored features of Usability and put forth possibility of investigation to enhance overall Usability within FOSS system.

\subsection{SKETCHING THE BACKGROUND}

The free software movement

The free software movement started in 1983 (Bollier, 1999). But, at that time also there existed some products i.e. software that exactly or almost fit the definition of FOSS. Those earlier projects provided the freedom to study, use, modify and redistribute them but they were not the part of an organized movement to spread the practice, the philosophy or message of FOSS. The FOSS movement was launched by Richard Stallman (Vernudóttir, 2010).

Two different groups laid down the foundations for FOSS (Bretthauer, 2001) movement With a view to develop a free operating system, Richard Stallman (on the US east coast) decided to start GNU project and a free software foundation. So, he quit his job. At that time he was working as a programmer at the MIT AI lab.On the other hand a group named Computer Science Research Group (CSRG) of the University of California at Berkeley (on the US west coast) was instrumental in improving the UNIX system. A number of applications were also being built which collectively became "BSD Unix" (Berkeley Software Distribution). 
Being the longest story among all the stories related to software

It can be said that in the beginning there were only free software that existed. Proprietary software was born later on but very quickly it started dominating the software industry. In 1960s when IBM and others sold their first large scale commercial computers, they came up with some software which fit the definition of FOSS. It was in late 1960s that situation changed after "unbundling" of IBM software (Wheeler, 2015). In mid-1970s proprietary software started capturing the market.

\section{RESEARCH OBJECTIVES}

This paper aims at identifying new attributes of FOSS. It also takes into account the possibility of modifying the existing attributes. The idea behind this exploration is to facilitate FOSS evaluators in their work. In an attempt to understand FOSS in terms of its attributes the primary characteristics of FOSS namely Usability and Maintainability were pin pointed. Apart from analysing the desired characteristics of FOSS in terms of their attributes, it was also tried to determine if it is possible to hypothesise and establish the association between the above said two prime characteristics of FOSS. Determination of this sort of relationship is very important keeping in view the evaluation of present status of FOSS in India as far as the software industry is concerned. It was also essential to know the level of knowledge and understanding of people involved in various FOSS issues. Another important aspect that was needed to be explored was to become aware of the facts and figures related to the involvement of various professionals involved in a variety of FOSS related activities.

\subsection{DEFINITION}

\section{FREE AND OPEN SOURCE SOFTWARE}

Free and Open-source software is computer software with its source code made available with a license in which the copyright holder provides the rights to study, change and distribute the software to anyone and for any purpose (Laurent and Andrew, 2008).The FOSS is generally available free of cost and can be obtained through different sources (like internet etc.). Whereas, Closed Source Software also called proprietary software (e.g. Microsoft Windows and MS-Office) is available in the market with a price tag. But, it is important to know that in case of FOSS also the proprietary components and services may be charged for.

\subsection{LICENSES}

The FOSS licence gives you the freedom to attain it free of cost and ensures that the software can be changed and shared without any restriction (Lee, 1999).In general there are three categories in which the FOSS licenses may be put together as evident from TABLE 1 (Alspaugh et al., 2012).

Table 1: Types of software licenses

\begin{tabular}{|l|l|l|}
\hline License Type & Also known As & Examples \\
\hline Permissive & Academic & Apache, BSD, MIT \\
\hline Reciprocal & Copyleft & MPL, LGPL \\
\hline Propagating & Strong Copyleft & GPL, AGPL \\
\hline
\end{tabular}

\section{RESEARCH METHODOLOGY}

Empirical approach was adopted to carry out this research endeavour. As far as the data collection is concerned the Simple random sampling was used to select the true representative of the population. Both the Qualitative and quantitative approaches were instrumental during this process. The first approach was used to carry out data collection and latter for data analysis respectively. The qualitative approach was concerned with carrying out interviews and recording the observations of participants. The Quantitative methods involved the use of a well structured questionnaire in order to collect data that was then analyzed by employing different Statistical tools/ methods like mean score, Coefficient of Variance, Cronbach's Alpha and fisher's exact test. To establish the various attributes of Usability, a pilot study was also planned and implemented before heading towards the actual research attempt. These attributes (Sidhu and Khurmi, 2016) are: Quick comprehension, Proficiency, Knowledge acquisition, Guidance/Help, Informative documentation, System support, Appealing manifestation,-Well-responsive system, Dynamic functionality, Provided directivity, Reliance, Error control, Full user control, Satisfaction, General user support, Active feedback, User oriented, Consistent and clear screen display, User-friendly interface and Norms and standards. The various established attributes of Maintainability that were taken into account are (Bertoa and Vallecillo, 2002): No system crash/hang, Error detection and analysis, Tailorability, Extensible, Self-testing, Manoeuvre control, Familiar looks, Scalability, Easily updateable.

\section{RESULTS AND FINDINGS}

5.1 Understanding and Awareness Regarding FOSS 
The awareness and understanding regarding FOSS are important factors to know the extent to which FOSS can be used. In this context, the respondents were explored regarding their awareness about FOSS in terms of being aware of concepts to some extent, well informed about FOSS but still need more information, sufficient knowledge and in-depth knowledge. As far as their understanding of FOSS is concerned, it has been judged through their perception in terms of free distribution (unlike proprietary software, distribution without any restriction or constraint under FOSS license that facilitates its circulation rather than hindering it), access to source code, modification of source code, redistribution of modified software and unrestricted use of FOSS (Figure 1).

When asked, all the respondents voted affirmatively regarding their understanding of FOSS that it can be distributed freely. If we look at the figures we find that majority of respondents ( 86 percent) are fully aware about FOSS. Majority of the remaining respondents agree to this that they have sufficient information about FOSS when it comes to its free distribution and there are only marginal number of respondents who show some hesitation about this fact and so, think about acquiring some additional knowledge about FOSS before saying anything with certainty in this regard as evident from Figure 1.FOSS also provides access to the source code. When the respondents were enquired about their understanding regarding modifying the source code of FOSS, they again proved that they had more than sufficient information about this fact. Eighty six percent respondents have depicted their awareness about this characteristic of FOSS (Figure 1). Since FOSS provides the facility to modify the source code which may subsequently be useful to the users. So, if the modification in the source code proves authentic then the company/community providing FOSS, redistributes the modified software among the users. The fact about the redistribution of FOSS is also common among the FOSS professionals. Most of the respondents answered positively when enquired about this characteristic of FOSS. Although, a couple of them had some doubt about it. Majority of them confirmed that they had complete and thorough knowledge about this feature of FOSS. Some others (very marginal in number) seemed to be a little bit conscious about acquiring some more information about FOSS in this regard as obvious from Figure 1.

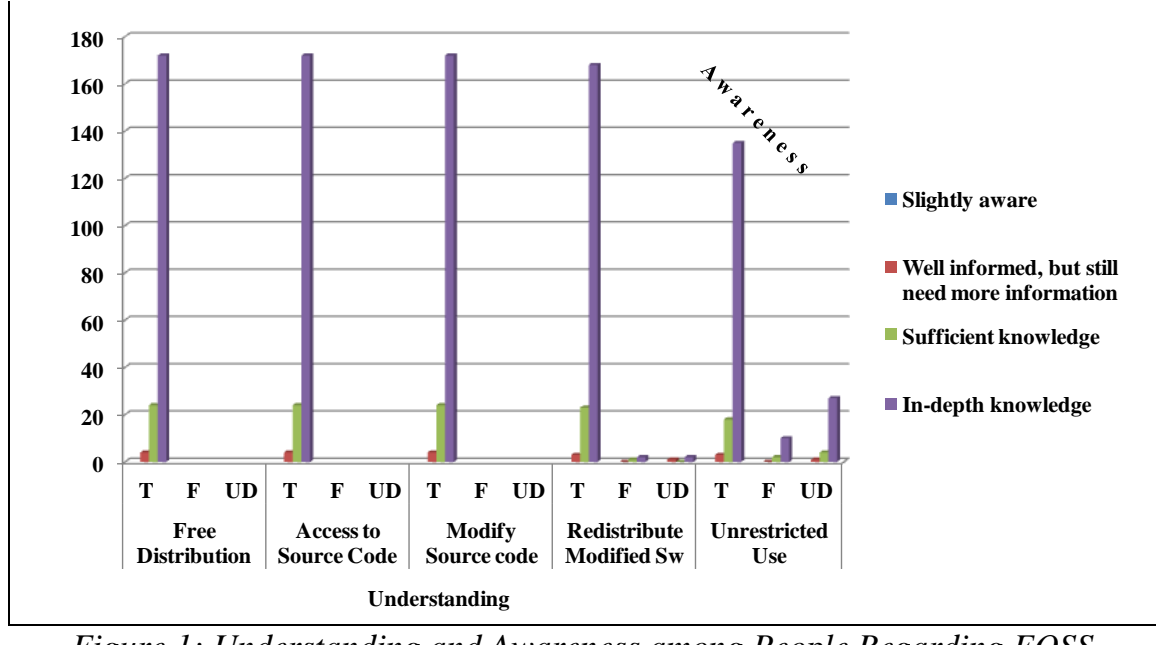

Figure 1: Understanding and Awareness among People Regarding FOSS

People who are having understanding regarding FOSS in terms of free distribution, access to source code, modify source code, redistribute modified software are using and involved in these characteristics. Many of the people are unaware about the existence of licenses and unrestricted use of FOSS besides some have doubts (Figure 1) over the fact that the FOSS licenses promote its utilization without putting any undue constraint on its use and distribution (which is very promising and positive aspect about FOSS).

\subsection{User Activities Concerning FOSS}

Since software are associated with such issues as code review, coding, testing, documentation, bug reports etc. and FOSS are no exception in this regard. This has been established in the Figure 2 that FOSS professionals are actively involved in such activities. Respondents were enquired about the activities they follow by getting involved in FOSS. Most important activities which are performed by FOSS people are documentation (64 percent), coding (63 percent) and bug reporting (54 percent) as clear from Figure 2. FOSS users take these activities as a challenge hence; they are able to get involved in these activities. Therefore, the information provided by this table reveals that FOSS community is actively involved in upgrading and maintaining FOSS. This proves to be a wonderful service to the society at almost negligible cost. 


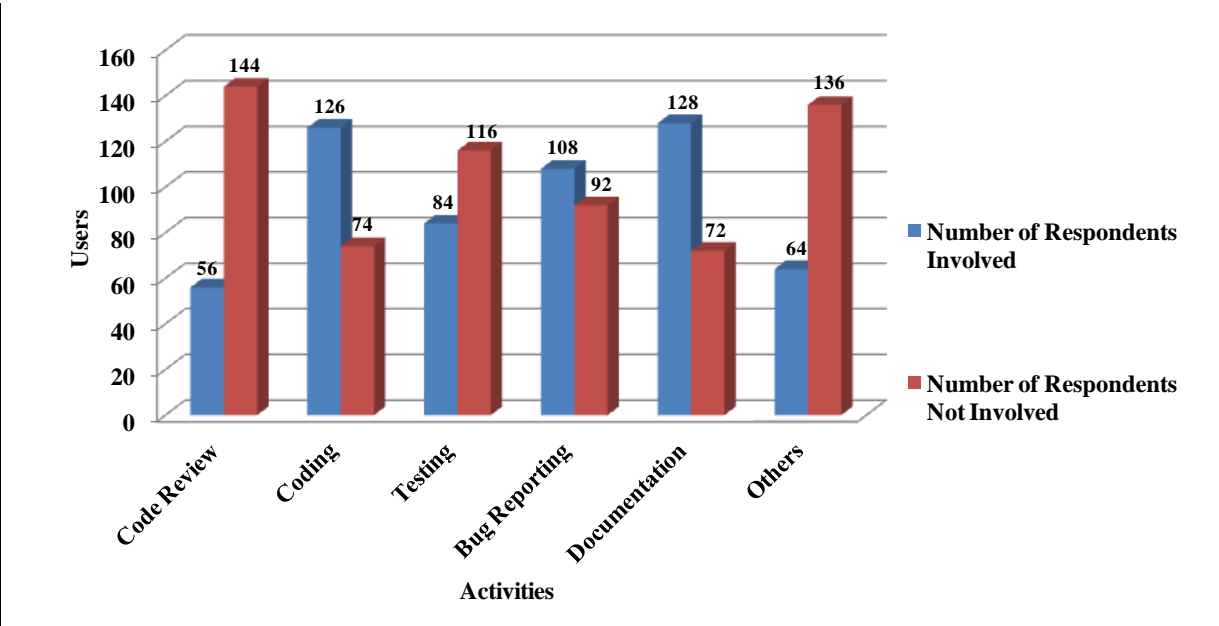

Figure 2: User Activities Concerning FOSS

The two Open Source Software used for analysis were BOSS and LINUX shown in Figure 2 through pairs of vertical structures with each pair showing BOSS as first vertical construct and LINUX as second vertical construct respectively. The figures reveal that maximum number of respondents are involved in coding and documentation (about 64 percent) of FOSS. Coding being the most important part of software development supported by documentation (to understand the developed software) seems to be the favourite tasks of the software professionals performed by them in the FOSS arena (Figure 2). The data seems to be giving quite logical results as the coding of the any software is most crucial part of the entire software development life cycle among other phases because it is this part which converts a virtual concept into reality. Also, a good coding construct supported by a careful documentation of each and every aspect of the software makes a software very user friendly and also compatible with user's orientation of mind. Although, until recent times FOSS were considered to be poorly documented.By taking the position next to coding and documentation, bug reporting seems to be substantially important as clear from Figure 2. From practical point of view this task is an imperative one as the software need to be rigorously tested and reported from the point of view of its functionality before being released to masses. So, testing has its own position in this entire scenario. Testing seems to follow bug reporting very closely because a good number of respondents confirm that they carry out this activity giving it a special attention that it deserves. The data also confirms the close association between these two activities as far as the objective of making the software an error free platform is concerned for its global acceptance. The data also discloses the fact that a fairly good number of respondents are also involved in other activities Figure 2 apart from the above mentioned tasks related to FOSS. These activities may vary widely in different aspects depending upon the purpose for which they are performed. Some people may be involved simply in the use of FOSS as an end user just to use the software for fulfilling their routine needs or to carry out their usual tasks. Some of them may be having other serious business related to activities such as version control of the software. It depends upon the role you are playing while dealing with FOSS (i.e. whether you are acting as user, developer or as an analyst).It is also important to cite a likely fact here that it is very much possible for a developer to be the user of FOSS that he/she is developing. But, the reverse does not seem to happen so easily because you need to have in depth knowledge about different issues concerned with the software development before you can swap your role to become a developer.

\subsection{Reliability and Validity of Data}

To determine the reliability and validity of the data obtained from this research effort the Cronbach's alpha test was conducted on the primary database. It gives us the estimate of internal consistency of a scale.

Table 2: Cronbach's alpha for Usability Data

\begin{tabular}{|l|l|lr|}
\hline \multicolumn{4}{|l|}{ Reliability Statistics } \\
\hline $\begin{array}{l}\text { Cronbach's } \\
\text { Alpha }\end{array}$ & $\begin{array}{l}\text { N of } \\
\text { Items }\end{array}$ & VARIABLES & \\
\hline .690 & 6 & $\begin{array}{l}\text { Learnability, } \\
\text { Operability, } \\
\text { Complexity Usability, compliance. }\end{array}$ & $\begin{array}{r}\text { Understandability, } \\
\text { Attractiveness, }\end{array}$ \\
\hline
\end{tabular}

The value of alpha lies somewhere between 0 and 1 . Internal consistency signifies the extent to which all the items are interrelated to each other in a test. It is very important to check the internal consistency of data before 
applying any sort of test on it for research purpose to ensure its reliability. The statistics after applying the Cronbach's alpha test on Usability and Maintainability are shown in TABLE 2 and TABLE 3. A value of 0.7 or above for Cronbach's alpha is considered to be acceptable. It is evident from the two Cronbach's alpha values (i.e. 0.690 and 0.707 from TABLE 2 and TABLE 3 respectively.) that the data is pretty reliable and can be subjected to hypothesis testing.

Table 3: Cronbach's alpha for Maintainability Data

\begin{tabular}{|l|l|lr|}
\hline \multicolumn{2}{|l|}{ Reliability Statistics } & \multicolumn{2}{l|}{ of } \\
Cronbach's & $\begin{array}{l}\text { N } \text { of } \\
\text { Items }\end{array}$ & VARIABLES & \\
\hline & & $\begin{array}{l}\text { Stability, } \\
\text { Changeability, } \\
\text { Trackability, } \\
\text { Upgradeability. }\end{array}$ & $\begin{array}{r}\text { Testability, } \\
\text { Flexibility, }\end{array}$ \\
\hline
\end{tabular}

5.4 Association between Usability \& Maintainability

Usability (Usability along with its attributes is depicted in Figure 4) and Maintainability (existing in terms of Stability, Analyzability, Changeability, Testability, Trackability, Flexibility and Upgradeability) are very prominent characteristics of FOSS. Once we get the software (FOSS) and start using it, Maintainability characteristic comes into play. It means it is operational once you attain the software and start realizing it's Usability.

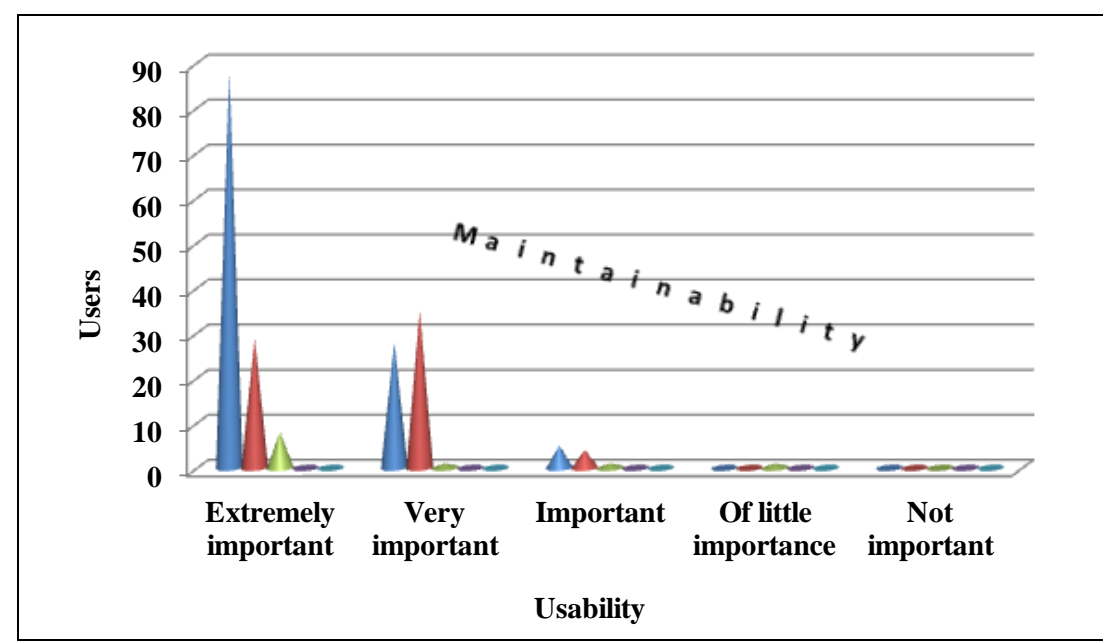

Figure 3: Association between Usability \& Maintainability

So, if we say that Usability of the software is followed by its Maintainability then a question arises that do we need to find out association between these two parameters of FOSS? The likely answer to this question lies in the positive attitude of respondents towards both of these characteristics of FOSS.As a matter of fact our approach should be towards finding some probable linearity between these two factors. But, actual results of survey may have inclination towards either side (i.e. in favour or against). The Usability of FOSS is described in terms of Learnability, Understandability, Operability, Attractiveness, Complexity and Usability Compliance (Seffah et al., 2001). The various Usability sub-characteristics and their attributes can be described as shown in TABLE 4

Now, if we follow logical reasoning then we should approach this deduction that there is some dependability between these two concepts (i.e. Usability and Maintainability). So, we try to establish some sort of association between these two (Figure 3). The reason behind this effort is that it seems that if the FOSS product is poor in context of Usability then obviously it is going to have adverse effect on Stability, Flexibility and Upgradeability of software in terms of Operability, Usability Compliance and Complexity. Any sort of deterioration in theUsability standard of FOSS will result in problems that will arise in terms of its Maintainability. So, at his moment of time we need to hypothesize the concept we are trying to prove based on our primary database obtained as a result of the survey for carrying out this research activity. To provide the base to the observations being considered the authors opted for statistical analysis of the available data. Keeping in view the attributes of the two characteristics (i.e. Usability and Maintainability) of FOSS, the Fisher's Exact Test was applied to test and hypothesize (See TABLE $5 \& 6$ ) if there exists any relationship between the above said two characteristics of FOSS. The significant value of $.000(<.05)$, as apparent from TABLE 6, undoubtedly shows the legitimacy of the alternate hypothesis that there definitely exist some relationship between these two 
characteristics of FOSS. So, we can say with certainty based on the statistical results that the Stability, Flexibility, Upgradeability etc. of FOSS can easily be handled provided the Operability, Usability Compliance, Complexity etc. are well managed in FOSS.

Table 4: Usability in terms of its proposed/modified attributes

\begin{tabular}{|c|c|}
\hline $\mathbf{S N}$ & Characteristic-Sub Characteristic -Attributes(s) \\
\hline & Usability \\
\hline & Learnability and its attribute(s) \\
\hline 1 & $\begin{array}{l}\text { To learn new functions of FOSS is quite easy (Quick } \\
\text { comprehension). }\end{array}$ \\
\hline 2 & $\begin{array}{l}\text { After thoroughly going through FOSS, it is rarely needed to take } \\
\text { help of documentation (Proficiency). }\end{array}$ \\
\hline \multirow[t]{2}{*}{3} & $\begin{array}{l}\text { It is possible to quickly gain knowledge of the FOSS commands } \\
\text { (Knowledge acquisition). }\end{array}$ \\
\hline & Understandability and its attribute(s) \\
\hline 1 & Menus in FOSS appear to be rational (Guidance/Help). \\
\hline 2 & $\begin{array}{l}\text { The FOSS documentation provides sufficient knowledge about it } \\
\text { (Informative documentation). }\end{array}$ \\
\hline 3 & $\begin{array}{l}\text { FOSS provides relevant instructions and prompts (System } \\
\text { support). }\end{array}$ \\
\hline \multirow[t]{2}{*}{4} & $\begin{array}{l}\text { The presentation of system information in FOSS is lucid and } \\
\text { reasonable (Appealing manifestation). }\end{array}$ \\
\hline & Operability and its attribute(s) \\
\hline 1 & $\begin{array}{l}\text { FOSS is significantly efficient in its responses to the } \\
\text { corresponding inputs (Well-responsive system). }\end{array}$ \\
\hline 2 & $\begin{array}{l}\text { FOSS provides ease of task switching that is it is possible to easily } \\
\text { switch between operations (Dynamic functionality). }\end{array}$ \\
\hline \multirow[t]{2}{*}{3} & $\begin{array}{l}\text { FOSS enables its users to have full functional control on it } \\
\text { (Provided directivity). }\end{array}$ \\
\hline & Attractiveness and its attribute(s) \\
\hline 1 & a user friendly environment (Reliance). \\
\hline 2 & $\begin{array}{l}\text { FOSS permits exploration of its various menus/tabs without any } \\
\text { problem apprehension (Error control). }\end{array}$ \\
\hline 3 & $\begin{array}{l}\text { FOSS does not pose any problem in my routine work (Full user } \\
\text { control). }\end{array}$ \\
\hline 4 & FOSS functioning is up to the mark (Satisfaction). \\
\hline 5 & $\begin{array}{l}\text { FOSS adequately provides timely information to its user as and } \\
\text { when required (General user support). }\end{array}$ \\
\hline 6 & $\begin{array}{l}\text { FOSS displays relevant information on the screen regarding the } \\
\text { ongoing task (Active feedback). }\end{array}$ \\
\hline 7 & FOSS yields likely results (User oriented). \\
\hline \multirow[t]{2}{*}{8} & $\begin{array}{l}\text { FOSS provides attractive screen presentation (Consistent and clear } \\
\text { screen display). }\end{array}$ \\
\hline & Complexity and its attribute(s) \\
\hline \multirow[t]{2}{*}{1} & $\begin{array}{l}\text { FOSS system interface is sufficiently self-explanatory (User- } \\
\text { friendly interface). }\end{array}$ \\
\hline & Usability compliance and its attribute(s) \\
\hline 1 & $\begin{array}{l}\text { FOSS user-interface is in accordance with the industry standards } \\
\text { and follows the general conventions and regulations (Norms and } \\
\text { standards). }\end{array}$ \\
\hline
\end{tabular}

Table 5: SPSS Output for Usability \& Maintainability Crosstabulation

\begin{tabular}{|l|l|l|l|l|l|l|}
\hline Usability * Maintainability Crosstabulation \\
\hline \multicolumn{5}{|c|}{} & \multicolumn{2}{l}{ Usability } \\
\cline { 2 - 8 } & 1 & 2 & 3 & 4 & \\
\hline \multirow{3}{*}{ Maintainability } & 1 & 88 & 28 & 5 & 0 & 121 \\
\cline { 2 - 8 } & 2 & 29 & 35 & 4 & 0 & 68 \\
\cline { 2 - 7 } & 3 & 8 & 1 & 1 & 1 & 11 \\
\hline
\end{tabular}




\begin{tabular}{|l|l|l|l|l|l|l|}
\hline & 4 & 0 & 0 & 0 & 0 & 0 \\
\hline Total & & 125 & 64 & 10 & 1 & 200 \\
\hline
\end{tabular}

Table 6: SPSS output for Fisher's Exact Test

\begin{tabular}{|l|l|l|l|l|l|}
\hline \multicolumn{2}{|l|}{ Chi-Square Tests } & Value Df & $\begin{array}{l}\text { Asymptotic } \\
\text { Significance } \\
(2 \text {-sided })\end{array}$ & $\begin{array}{l}\text { Exact Sig. } \\
(2 \text {-sided })\end{array}$ & $\begin{array}{l}\text { Exact Sig. } \\
(1 \text {-sided) }\end{array}$ \\
\hline Pearson Chi-Square & 37.163 & 6 & .000 & .000 & \\
\hline Likelihood Ratio & 25.920 & 6 & .000 & .000 & \\
\hline Fisher's Exact Test & 26.509 & & & $\mathbf{. 0 0 0}$ & .002 \\
\hline $\begin{array}{l}\text { Linear-by-Linear } \\
\text { Association }\end{array}$ & 9.304 & 1 & .002 & .003 & \\
\hline N of Valid Cases & 200 & & & & \\
\hline
\end{tabular}

\subsection{Discussion}

These various sources of information are helpful in improving the general awareness of people about FOSS. From the results of the survey it can be concluded that majority of the respondents were aware of such issues like access to source code, modification of source code, free distribution/redistribution of FOSS and its unrestricted use. This shows the level of awareness of FOSS people about it which, no doubt is fairly high. So, it can be said more and more people are becoming aware of FOSS technologies with the advent FOSS era although the presence of FOSS in the software industry is very old. This increasing understanding about the FOSS in the present times especially among the new entrants seems to be the root cause of emerging status of FOSS in India. It can also be seen from the survey results that out of total number of respondents majority of them had in-depth knowledge about FOSS issues signifying that people involved in FOSS are very much passionate about it.

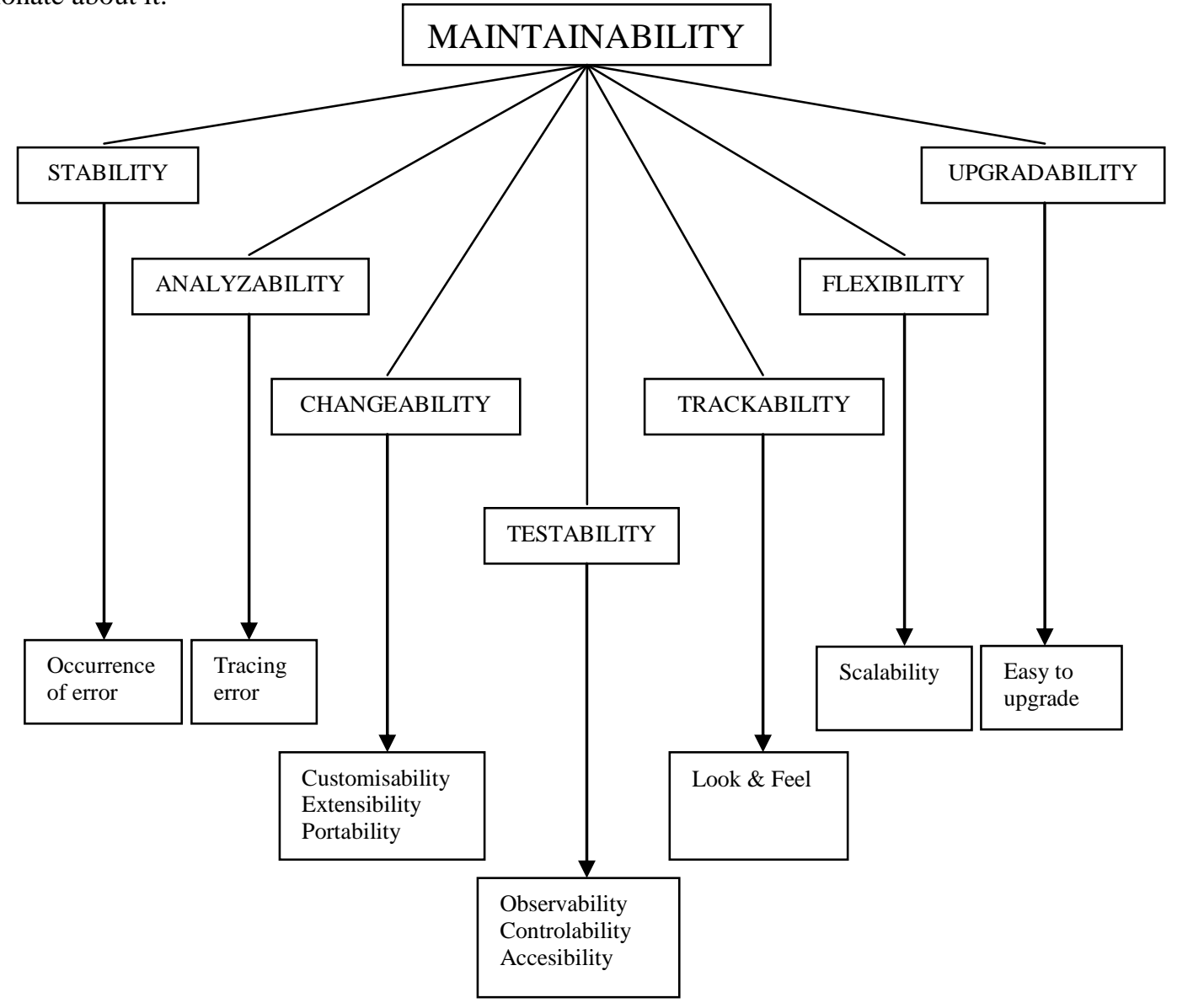

Figure 4: Graphical Representation of Maintainability in Terms of its Sub-Characteristics \& Attributes 
Further, it has been seen that coding and documentation are passion of advanced FOSS users. FOSS professionals are also actively involved in the activities such as Code Review, testing and bug reporting. The results signify that FOSS people enjoy such sessions with FOSS. All these activities being performed by the FOSS people indicate that FOSS is getting rich in its heritage. This is because that earlier the FOSS was not considered to be perfect in most of the areas especially in case of documentation related issues. But, the results of the survey give sufficient ground to believe that FOSS community has awakened and have started paying attention to the sensitive issues concerned with a software which were deeply taken care of in case of proprietary software only. This also shows the increasing bonding between the FOSS professionals existing in the vast swath across the world as it is obvious that the various FOSS issues can be handled only with mutual cooperation among the professional committed towards a common belief.Another important aspect of this research activity was to determine if there exists any relationship between the fundamental characteristics (Usability and Maintainability) of FOSS. The outcome of this empirical research is quite interesting showing that there holds a bond between the two basic characteristics of FOSS. This association or dependability among these underlying characteristics of FOSS is vital too. This is because this relationship shows that if FOSS can be suited to a new environment in which it is being installed only then it is useful from usage point of view thereby making sense for its maintenance or Maintainability, to be more precise. It has been established that Usability is considered in terms of Learnability, Understandability, Operability, Attractiveness, Complexity and Usability Compliance with their respective attributes considered for this empirical research. Whereas Maintainability is taken in terms of Stability, Analyzability, Changeability, Testability, Trackability, Flexibility and Upgradeability again with their respective attributes proposed in this research endeavour.

\section{CONCLUSION}

The increasing understanding and awareness about the FOSS related issues/concepts among the people involved or getting involved in FOSS is becoming a driving force as far as the uplift of FOSS is concerned in the software market or the society in general. As a common man if one is aware of something that is beneficial for him/her and also, that can be obtained at almost negligible cost then obviously the chances of that product/concept getting absorbed somewhere greatly increases especially in a country where inflation rate is high and per capita income is low. So, it is just a matter of time. In other words, the only thing that matters is that when you come to know about such product/object and how much you can digest about it to make proper use of it. Leaving apart the technicalities concerned the important aspect is the ease use of some commodity/product and its usefulness (may be a software or anything else) that become the root cause of its acceptance by the masses. It has been clearly indicted by this empirical study that FOSS is gaining ground as far as its technical knowhow is concerned among its users. This clearly indicates that more and more number of people are becoming interested or getting involved in the FOSS. The main reason behind this changing picture concerning FOSS may be attributed to the fact that the crucial areas (e.g. documentation) that were considered to be weaker in the past have been pin pointed by the professionals in the present scenario to make FOSS a true alternative to proprietary software.

\subsection{LIMITATIONS}

This study involves only two of the key characteristics concerning FOSS. This empirical exploration can be expanded to take into account other vital characteristics of FOSS like its Functionality etc. In addition to it, Usability of FOSS can be seen from different angles considering other pertinent attributes associated with FOSS, those need to be acknowledged, if required. In this empirical endeavour only the attributes of the undertaken characteristics (i.e. Usability and Maintainability) were highlighted (in terms of some of the new ones those were proposed or the present ones that have been modified). It is quite possible to identify some new sub-characteristics of the considered characteristics in this research effort. Also, the existing ones can be possibly modified (if needed). But, these issues have not been handled in the present approach. The basic limitation concerned with this research study is the bias factor that gets involved while handling the response of participants. The intensity of biasness significantly influences the research's outcome. This particular empirical study does not involve any method that is competent in handling fuzziness. An appropriate algorithm may be involved so as to deal with the biasness in the responses provided by the respondents. Such use of a suitable method competent enough to handle fuzziness and biasness appreciably perks up the consistency and precision of the results. It then becomes easier to have a broader view of the outcome of an empirical research so as to include the whole of the population if such method is engaged.

There are a good number of other imperative characteristics of FOSS which need consideration (such as Reliability, Efficiency and Functionality). This empirical research can be extended by determining their suitable sub-characteristics and the corresponding attributes of these sub-characteristics. It will assist in having a 
thorough understanding regarding the existing standing of FOSS in the market. In addition to this some fitting techniques competent of managing biasness and fuzziness in the feedback attained from the people concerned with FOSS can be employed to have more realistic outcomes. It will result in absolute exploration of FOSS.

\section{REFRENCES}

[1] Alspaugh, T. A., Asuncion, H. U. and Scacchi, W. (2012). Software licenses, open source components, and open architectures. In: Aligning Enterprise, System, and Software Architectures (Eds. I. Mistr' $1 k$, A. Tang, et al.) IGI Global, pp 58-79.

[2] Bertoa, M. and Vallecillo, A. (2002). Quality attributes for COTS components. In: Proceedings of the Sixth ECOOP Workshop on Quantitative Approaches in Object-Oriented Software Engineering, Malaga, Spain. pp. 54-66.

[3] Boivie, I., Gulliksen, J. and Göransson, B. (2005). The lonesome cowboy: A study of the usability designer's role in systems development. Interacting with Computers 18: 601-634.

[4] Bollier, D. (1999). The power of openness. Why citizens, education, government and business should care about the coming revolution in open source code software. Retrieved from http://www.opencode.org/h2o/

[5] Bretthauer, D. (2001). Open Source Software: A History, University of Connecticut. DigitalCommons@UConn, UConn Libraries Published Works, University of Connecticut Libraries.

[6] Hall, J. (2014). Usability themes in open source software. In Scientific and Technical Communication (STC) Plan C.

[7] ISO/IEC 9241-11 (1998). Ergonomic requirements for office work with visual display terminals (VDT)s - Part 11 Guidance on usability.

[8] Laurent, S. and Andrew, M. (2008). Understanding Open Source and Free Software Licensing, O'Reilly Press, Sebastopol, CA.

[9] Lee, S. H. (1999). Open source software licensing. Available online:cyber.law. harvard.edu/openlaw/ gpl.pdf.

[10] Nielsen, J. (1993). Usability engineering. Boston, Academic Press.

[11] Seffah, A., Kececi, N. and Donyaee, M. (2001). QUIM: A Framework for Quantifying Usability Metrics in Software Quality Models. Second Asia-Pacific Conference on Quality Software (APAQS'01). p. 0311.

[12] Sidhu, H. S. and Khurmi, S. S. (2016). Analyzing Open Source Software in Terms of Its Characteristics and Establishing New Paradigms.

[13] Vernudóttir, H. B. (2010). The Use of Free and Open Source Software by Icelandic Software Developers. Research report. B.Sc. Computer Science. Springler, New York.

[14] Wheeler, D. A. (2015). Why Open Source Software / Free Software (OSS/FS, FLOSS, or FOSS)? Look at the Numbers! Case study. 